or "What a lie", or "How could I have said so"? or demanded at once that she should be sent for. Yet, he never on one single occasion, before others, spoke to Mrs. Cox on the subject. The only reasonable answer to this criticism is that he did not understand that Mrs. Cox had accused him of taking poison wilfully; and I do not see that any of the medical men put it categorically before him that she had done so.

After carefully reading all the evidence on the subject of Mrs. Cox informing the medical men that he had taken poison, I see no reason to doubt that whilst, for fairly sufficient reasons, she did not tell Dr. Moore, yet she believed that she did tell Mr. Harrison; though, in doing so, she mixed up her statement that he had taken poison with her opinion that the poison he had taken was chloroform. Afterwards, finding the doctors thought he had not taken chloroform, and seemed to doubt his having taken any poison, she repeated her statement to Mr. Royes Bell and Dr. Johnson. Her reasons for not telling Dr. Moore are, that she thought it would be such a scandal that he should have taken poison on account of jealousy for his wife; and that, when he recovered (as having, in her opinion, only taken chloroform, he would), Mr. Bravo would be so angry at the circumstance having been made known.

Mr. Bravo seems to have expressed no desire to recover, and no surprise at the suddenness of his illness, or at the fact that-putting poison on one side-the nature of it was obscure; or curiosity to know how, if he had taken poison accidentally, he could have got hold of it, or who could have given it to him intentionally. On the contrary, he determinately, and once rudely, put a stop to any such disquisitions. All this required the courage which he was said by his stepfather to possess.

With regard to motive, he was quick in temper; had (quantum valeat) a sunstroke some years ago ; was so dominated by an irritating and depressing idea as to have been little less than a monomaniac ; had that day had the subject of his monomania prominently before him; had threatened to commit suicide; had a Turkish bath in the morning, and $a$ warm bath in the afternoon. He had been suffering more or less from facial neuralgia for several days; and at dinner had nervous twitchings of the face, and looked ill and seemed irritable. In the morning, he had received an annoying letter from his mother; and in the afternoon, one of a similar character from his father; had that afternoon had his nervous system rudely shaken; and, on going up to bed, had been agitated by an exhibition of his wife's weakness in a matter which was known to annoy him intensely. Under such circumstances, an insane impulse is very far from surprising.

It is true, there are arguments on the other side; but these have been so fully and repeatedly set forward, that it is needless to repeat them. It is not to be denied that these are of some weight. There. fore, though I lean to the probability of suicide, as against murder, probably the sound conclusion to adopt is that, though Mr. Bravo was poisoned by antimony, there is not sufficient evidence to say positively how or in what shape it was introduced into the system.

4. That he was murdered.

The discussion of this question is virtually included in that of the preceding proposition, for it cannot be denied that the issue in this case is practically murder or suicide. I have only to add that, on a careful perusal of the evidence, sufficient proof of the existence in the mind or minds of any person or persons of hopes, fears, desires, wishes, or regrets, which might be supposed capable of supplying an adequate motive for crime, has not been established.

The fifth proposition I do not care to discuss, though arguments in its favour might be adduced.

It is more satisfactory to the sensational cravings of the multitude to believe in a great crime than in a great folly or in an act of insanity : a human weakness which may have contributed to produce the la st verdict. It may be an inducement to some to believe in the crime, to admit that it is scarcely possible they can ever be proved to be in the wrong; whereas those who believe in the folly may, if they are wrong, be convicted of their error.

\section{THE OVUM-FORCEPS.}

IN some few cases of premature expulsion of the ovum, I have found great difficulty in removing the mass (placental or other) from the uterus by the ordinary ovum-forceps ; in some cases because the os uteri has not been sufficiently open, and in other cases because the forceps would not reach in consequence of massive buttocks ; I, therefore, had a pair constructed (which I exhibited at Sheffield), two inches longer than the usual pattern in the handle, and measuring only half an inch wide at the fenestra. These will, as I have proved, pass and reach in cases where the old pattern is useless. In some cases, where it has been necessary to empty the uterus, I have owed my success to this modification.

\author{
C H AOS : \\ AS EXEMPLIFIED IN CENTRAL AND LOCAL SANITARY \\ ADMINISTRATION.* \\ BY JOSEPH ROGERS, M.D., \\ Formerly President of the Poor-Law Medical Officers' Association.
}

ON November 29th, 1870, a meeting was held in London, which was numerously attended by metropolitan medical officers of health, Poorlaw medical officers, and by gentlemen interested in sanitary reform. One object of the meeting was to lay down some basis for concerted action between district Poor-law medical officers and health-officers. This was attempted by formulating certain propositions which had been drawn up by Dr. Rumsey, the late Dr. Anstie, and by myself. Those propositions were laid before the then President of the Poor-law Board, Mr. Goschen, and were also forwarded to the Royal Sanitary Commission, with the request that they might be printed in the appendix to their Report. I have a copy of the report of the meeting, which contains the text of those propositions; but I will not now read them unless desired, but will content myself with this observation, that, if they had been adopted by the Government who brought in the Public Health Bill, 1872, most of the anomalies which exist in our Poor-law medical and public health arrangements would have been removed. At the conclusion of my address, which was largely devoted to the elucidation of these propositions, Mr. James Lewis, Poor-law Inspector, then of the Registrar-General's Department, Somerset House, read a paper on Registration of Disease. This done, $\mathrm{Mr}$. Benson Baker proposed the following resolution: "That, in the opinion of this meeting, it is desirable that a general registration of all new cases of disease coming under treatment at the public cost, in workhouses and Poor-law districts, should be established; and that the medical officers of such workhouses and districts, as enjoying the largest opportunities of observing facts prejudicial to the public health, should be entrusted with the duty of making weekly, or, in times of epidemic, more frequent returns of cases actually coming under treatment, and of other facts concerning the spread of disease, to the health-officers of their respective districts." This resolution was seconded by the late Dr. Maunsell of Dublin, who came over specially to attend the meeting; and, after being supported by the late Dr. Letheby and others, was unanimously adopted, as well as the subsequent resolution recommending that Poor-law medical officers should be deputy health-officers in their respective districts. Looking back at what has since occurred, I regret that the term deputy was ever used: the respective classes of officers should have been health-officers and superintending health-officers. The report of that meeting was forwarded to the President of the Poor-law Board, Mr. Goschen, a gentleman whose perfect independence of action, foresight, and great intelligence, commanded the utmost confidence. Here let me observe that we had trusted that the outcome of the labours of the Royal Sanitary Commission would have been to suggest the formation of a Council of Public Health, to whose control would have been committed not only all matters relating to public hygiene, but the curative treatment of the necessitous sick. It was, therefore, with a feeling of dismay that we learnt that the powers of the Poor-law Board were to be enlarged, and that all the health-duties performed by the Medical Department of the Privy Council were to be absorbed in it. Still we had confidence that, as the services rendered by that department, and notably by that able man Mr. John Simon, were known and recognised wherever the English language was spoken, in any new arrangements that Medical Department would form a distinctive and prominent feature. Such might have been the case if Mr. Goschen had remained President; but, unfortunately, Mr. Childers became ill, Mr. Goschen was transferred to the Admiralty, and was succeeded by Mr. Stansfeld, who, like most doctrinaires, was as weak in practice as he was vigorous in theory, and who speedily exhibited himself as the instrament of those permanent lay officials of the Poor-law Board who, under the long reign of the late Mr. Henry Fleming, had contrived not only to bring the very name of that Board into general disrepute, but at one time had seriously imperilled its continued existence.

Here let me remark that the Local Government Board, like its predecessor the Poor-law Board, is a myth. Nominally, it consists of a President and certain members of the Cabinet; but, in reality, they

* Read before the Public Medicine Section at the Annual Meeting of the British Medical Association in Sheffield, August 1876 . 
never meet in council. Consequently it occurs, if the President be a weak man, that all initiative and governmental control is usurped by the permanent officials. Even if he be vigorous, it requires immense self-possession to enable him to hold his own.

If this could be justly asserted when the President was solely entrusted with the Poor-law destinies of the country, with what infnitely greater force should the existing arrangement be condemned, when, in addition to his Poor-law duties, he is entrusted with the control (nominal, I admit) of public health as well; and that, too, without any efficient guide to aid him by his counsel!

Some months prior to the introduction of the Public Health Bill, I had been engaged, conjointly with Mr. Corrance, late M.P. for East Suffolk, Dr. Rumsey, and others, in preparing a Bill which we had intended to bring before the House; but, learning that the Government had announced an intention to bring in a public health measure, we sought an interview with the President on February I 3 th, 1872. The promises held out to us covered so much of the ground on which we were, that, on retiring, we decided, unwisely as it turned out, to forego any action as regards our Bill until we saw more of the Government measure. At that interview, I noticed that, although our deputation had been arranged some days before, and although we were accompanied by several members of Parliament and leading sanitarians, the only officials in the room were Mr. H. Fleming and Mr. John Lambert. I was so struck by it, that immediately after the interview I called public attention to this fact. Some few weeks afterwards, I accompanied another deputation, formed by the Social Science, British Medical, and Poor-law Medical Officers' Associations, to the same Minister. On that occasion, Mr. Simon was present; but it was easy to see, by the way he sat in his chair, that it was, in all probability, the first time he had ever been in the room. Possibly he would not have been asked even then, if the press had not commented on his previous absence. You will, therefore, not be surprised to hear that he was never consulted respecting the clauses of the Public Health Bill; and that, from the time of the incorporation of his department in the Local Government Board, he was studiously ignored, until at last he resigned office; and, as practically no successor has been appointed, the lay and legal element is in complete ascendancy, and the Public Health Act, so far as the central department is concerned, is administered by gentlemen wholly ignorant of even the rudiments of public hygiene: the first illustration of that chaos which $I$ believe hereafter. I shall make more apparent. After this, can it be wondered at that the returns and reports made by the various healthofficers, which are duly forwarded to the Local Government Board, excite no interest, find no readers, and are, as I am given to understand, not even acknowledged?

As you are aware, the Act divides England and Wales into urban and rural districts; the authority in urban districts being vested in the borough council, improvement commissioners, or the local board; in the rural, the boards of guardians. The incongruity of this arrangement was early pointed out, but without effect. Again, Mr. Stansfeld took powers to constitute the Poor-law medical officers the healthofficers in their respective districts. On the part of many of my Poorlaw medical brethren, who wrote to me from all parts of the country, I at once objected to these clauses, alleging as my reason that Poor-law medical officers were not, as a body, sufficiently independent to carry out the onerous duties proposed to be imposed on them ; but we were again overruled, this time, I regret to state, by the aid of certain of those who, as members of the Poor-law Medical Officers' Association, had worked loyally with us to secure the concession of becoming an integral part of a public health administration such as we had sketched at our meeting in 1870 , and had drafted in our Bill, but who fell off from us so soon as they found that the President had been so illadvised as to propose to place them in a position so different from that we had previously striven to obtain.

The Bill, however, became an Act, although many leading sanitary authorities pointed out to Mr. Stansfeld that the sole appointment of parochial medical officers as health-officers would not work. How soon this view was shown to be correct is well known. At first, the inspectors (the Poor-law ones, of course), Mr. Simon's staff being set aside, were instructed to urge on rural and urban sanitary authorities that they were to appoint the parish doctors as healthofficers, with some slight augmentation of their stipends; but so many refused to undertake the duty, that the same officials changed front, and advised the same authorities to combine so as to appoint one health-officer over a considerable area. This has taken place to this extent, that there are, or were, forty such combinations, which include two hundred and seventy-seven Poor-law unions; there being, exclusive of the metropolis, five hundred and ninety-nine separate unions in England and Wales.
In these combinations, no arrangement was made for obtaining that information as regards the outbreak of epidemic disease, which the Poor-law medical officers could most effectually supply. Indeed, the only source from which most of the health-officers could obtain a knowledge of what was going on in their districts, varying in area from 18,000 to 682,107 acres, was derived from the reports of the district registrars; and, owing to the delay in getting these reports, an epidemic had by that time either got firm hold of a locality or had worn itself out. It is true that an effort was made after a time by the central department to meet this lack of information, as was exhibited when Mr. John Lambert issued his circular letter to boards of guardians urging on them the advisability of requiring their district medical officers to return weekly reports of epidemic disease ; but, as no suggestion was made for any additional payment for the extra work entailed thereby, and as it was not in the bond, I need not state that it has been almost universally disregarded. I farther learn that five hundred and twenty-four urban appointments have been made, varying in population from many thousands, and salaries quite respectable in amount, down to townships of 296 inhabitants, such as Baldersby, Yorkshire, where the stipend is $£ 3: 3$. Here, again, let me note that, although half the stipend is paid from the Consolidated Fund, which ought to necessitate some principle in fixing the amount : as an instance in point, showing the absence of all such control, the health-officer for Acton, Middlesex, with a population of $4, \infty 00$, acreage 2,260 , receives $£ 70$; whilst the health-officer for Bedlington, Northumberland, with a population of 13,496 spread over 9,0 I I acres, receives only £40. Multitudes of similar anomalies as regards payment, population, and acreage, might be readily quoted.

In these urban appointments, it frequently happens that the healthofficer selected is a parochial medical officer, his colleagues in the same union being set aside. You can easily understand from this the amount of information which his confrères afford him. Similarly, there are two hundred and sixty-eight rural districts in which the same spirit of unnatural selection has been adopted; whilst there are one hundred and forty-six unions in which Mr. Stansfeld's plan for the appointment of the district Poor-law medical officers as sole health-officers in their respective districts has been carried out. As regards these latter appointments, they are absolutely ludicrous in their terms. Thus, in some a fair addition has been made to the paruchial pay; in others, the sum of $£^{2}: 2, £ 3: 0$, or $£ 3: 15$, is the annual honorarium. At Barnstaple, Devon-population 36,215, acreage 126,749-the district Poorlaw medical officers, eleven in number, receive a guinea for each report, and one shilling a mile one way. It would be interesting if we could learn how many reports have been made. In the New Forest, an increase of 20 per cent. is made on the yearly stipend. Of the large combinations, I find that the three most ill-formed are those of Oxfordshire, Berkshire, and Northamptonshire; the irregularities of the first two being due to adopting county boundaries, which, my informant states, are often of a most inconvenient kind, and correspond neither with watersheds, railway arrangements, nor anything else. $\mathrm{He}$ further states that, adopt what rule you please as regards combinations, you must have anomalies. This proves that the arrangements on which these combinations were made should not have been left to the voluntary association of certain authorities, but should have been settled with due regard to the possibility of their being easily and efficiently worked.

A good illustration of want of such arrangement is shown in the Gloucestershire combination, where in the middle of it are located the unions of Stroud and Whitminster : Stroud with a single health-officer, the six Poor-law medical officers being ignored; Whitminster, where the two Poor-law medical officers are appointed. Again, in Hertfordshire, the town of St. Albans has its health-officer, the St. Albans Rural Authority has another, and the rest of the county has combined; the districts of the medical officers forming concentric zones, like a target.

Turning to Yeovil, Somerset, I find that the officer of the rural district is one of the district medical officers ; his district covers 48,760 acres, contains thirty-six villages, and has a population of over 20,000 . This district is far too large for one person, however zealous he may be, effectively to work, notably if the officer be engaged in Poor-law and private practice. The stipend, originally fixed at $£ 150$, was cut down the second year to $£ 100$, and is now only $£ 75$. I cannot state why these successive reductions have been made; probably it is in consequence of his having exhibited too much zeal, or possibly of a growing feeling on the part of the rural authority that a health-officer is a needless expense ; whichever it may be, I have grounds for asserting that the less he does the better the guardians like it. I also learn that, if one of his Poor-law colleagues give him any information, that name generally comes out, and the odium is transferred from the paid and 
responsible officer to the unpaid one. It must be evident such a system cannot work; in fact it is, what I feel its authors (if they had any wits) must have foreseen, a muddle.

In the Yeovil urban district, population 8,000, the stipend is $£ 30$. Here, the medical officer of health gets no direct information from his Poor-law colleagues; all he has to rely on is the return of deaths from the registrar; and, from letters I have received from health-officers in different parts of the country, such is generally the rule throughout England and Wales. In the appendix to this paper, I have quoted extracts from such letters : they will be found to be very complete and suggestive.

Forty years before this Act came into operation, the division of the country into Poor-law unions was made. This was carried out by assistant commissioners. It is remarkable that, although the original Commission laid down certain general orders and regulations, the various boards of guardians were permitted to disregard them. Thus, one rule was that no district should have a population of more than 15,000, or an area of more than 15,000 acres, and that no officer should hold more than one district. My investigations into the administration of the Poor-law have taught me that there are 665 districts which exceed I 5,000 acres, and 205 which exceed I 5,000 persons; whilst there are 627 districts which are held by 29I medical officers, the salaries ranging, with medicines to find, from $8 \mathrm{~d}$. to $7 \mathrm{~s}$. a case of sickness. This muddle in our Poor-law medical relief system, equally with the discreditable chaos which holds in our sanitary arrangements, has arisen mainly from the same cause : the employment of ignorant lay officials to deal with purely medical matters.

Bad as the system is thus shown to be, with all its imperfections, more good would doubtless have accrued, notably in the larger combinations, if the officer could be assured that he would retain his post but this is by no means the case ; having voluntarily associated, each unit may withdraw if it please. Further than this, the officer may be dismissed; and this is pretty sure to be the case if he be sufficiently honest to do his duty, as in the instance of Dr. Deville of Harrogate; or to have his salary cut down, as in Yeovil, or as happened in the York rural district, at the suggestion of Lord Wenlock. Here, again, it is not a little remarkable that, in the early days of the new Poor-law, officers were similarly dismissed, or had their pay arbitrarily altered if they dared to take a humane view of their duties. It required years of public agitation ere such appointments were rendered permanent; indeed, we did not succeed in securing it in all districts until the period when Mr. Goschen became President.

The question now arises, What should be our aim? After careful consideration, I have come to the conclusion that every district Poorlaw medical officer should be constituted the health-officer of first instance ; that his duty in that capacity should be to report the occurrence of cases of epidemic disease, with their probable cause, to a superintending health-officer appointed to and over a considerable area. This latter should be paid a stipend sufficient to enable him to live independent of private practice; that, in order to compensate the district medical officer for the extra labour involved in such reports, etc., the Irish dispensary system (minus its faults) should be generally introduced; that, in sufficiently populous places, dispensers should be appointed, part of whose duty should consist in making returns daily of all $n \in w$ cases of sickness to the health-officer of the district, thereby sparing the labour of the district medical officer; and, in the few places where drugs are found by the guardians, as in Sheffield, some addition to the annual stipend should be accorded to the district medical officer as compensation for any such extra labour.

The absurd distinction between rural and urban districts should be abolished; and districts should in future be arranged with reference only to their being efficiently and economically worked.

Whilst cities of 70,000 inhabitants and upwards should be permitted to appoint their own health-officers, towns of lesser magnitude should be merged in the rural districts surrounding them.

County boards shou!d be established, consisting of justices of the peace and the elected chairman or vice-chairman of the board of guardians within the county, or district of the county, whose duty it should be to appoint the superintendent health-officer, and generally to order and control the sanitary requirements which might become necessary. Every superintendent health-officer, whose election has been confirmed by the Local Government Board, shall hold office until he die, or resign, or be dismissed after proved incompetence or neglect of duty; in fact, he should be placed in this particular on the same footing as the Poor-law medical officers.

The ordinary Poor-law inspectors should be relegated to their proper functions, that of controlling and, if possible, curtailing pauperism ; whilst the medical inspectors should be required to investigate all matters relating to public vaccination, the hygienic condition of work- houses and workhouse hospitals, the administration of medical relief, and generally all matters of an obscure character relating to large epidemic outbreaks, etc., which might from time to time occur in the superintending health-officer's districts.

Finally, and before all things, the Local Government Board should be reconstituted; the President should (in virtue of his office) be a Cabinet Minister, and not excluded from it as at present. Instead of presiding over colleagues that never attend, he should have as coadjutors an engineer of eminence, a barrister who has had some years practice at the bar, and a physician who has won his spurs in public medicine.

Can these suggestions be realised? Unquestionably, if the members of this powerful Association, sinking their individual differences of opinion as to the exact machinery of a public health administration, will only combine to use their huge political power in properly informing the legislature and the public as to the true course which should be followed if "sanitas sanitatum omnia sanitas" is to be other than empty words.

\section{APPENDIX.}

\section{Extracts from Letters from Medical Officers of Health, Poor-Law} Medical Officers, and others.

Midland.-I. Borough; population, II, 000 : lies in the centre of my district (which is twenty miles square); it has a medical officer of health to itself. This is very unpleasant, as we often come into collision. Infectious cases are constantly removed from the borough to my district. Having regard to area and population, my salary is the smallest in the kingdom.

2. I have no means of obtaining information regarding infectious diseases except through the inspectors of nuisances, and certificates of death which I get once a week.

3. The Poor-law Medical Officers have never been communicated with in my district on the subject of Mr. Lambert's circular of February $\mathrm{I}_{74}$; consequently no good result has followed it.

4. I know some medical officers of health and inspectors of nuisances who have been turned out of their appointments in consequence of giving evidence against members of local boards for existing nuisances. I am convinced that, unless medical officers of health are placed in a more independent position than they are at present, the object for which they were appointed will not be effectually carried out.

South.-I. Another writes: The extreme length is forty-eight miles ; the combined area comprises 311,556 acres; a population, in 1871 , of 140,215 , since then much increased. Is composed of seven rural and four urban districts. Lying within this area, but not included in the combination, are the urban districts of - and - on the southwest, and of - and - , in the north-east, containing 17,581 acres, and 52,275 inhabitants.

2. In half of the districts, compensation to a moderate amount is given, but not alike in all; the returns of sickness are given in irregularly, and in no one instance has a complete summary or return been found capable of being made out from them at the end of the quarter.

3. With few exceptions, no regular official intimation of outbreaks of epidemic disease has been received, doubtless owing to the improper absence of a suitable fee. The courtesy and kindness of various practitioners have, however, been conspicuous in privately keeping me au courant as to their appearance or prevalence.

4. The most serious muddle is that, with an apparently important and responsible position as health officers, we have no real power of executive action; however gross- the mischief, we can only point out the evil and the remedy-this the authority can notice or not, according to their humour.

Another serious muddle is the tedious and absurd steps required for the re-election of a medical officer of health; this ought not to be necessitated at all. The last shred of importance or dignity the holder of such office has is thus destroyed, and bitter regret is felt by the present officers of combined districts that they ever abandoned previous careers for such dependent though apparently tempting positions. Of course, much difference exists among authorities, but the point is, that where any are disposed to do nothing, they are privileged so to do.

Extreme South-IVist. - District consists of three urban and one rural; area, 73,804 ; population, I6,732. During the three years I have held office, I have received no advantage from information from Poorlaw Medical Officers in respect of the existence of epidemic disease. This arises from the fact that such officers have no compensation for the required services. It seems to me that this statement removes the necessity of taking your points seriatim. 
Midland.-Another writes : In answer to your second query, I think it will be sufficient to say that I experience this difficulty constantly. I give you the following instance. During the last six months of 1874 , and early part of 1875 , sixty-two cases of scarlatina occurred in fifteen cottages in a village of one of my rural districts, amongst a population of 258 persons, living in forty-eight houses. The disease was of a mild type, and only one death occurred, and that towards the end of the outbreak. This, of course, I got in my return of deaths; but did not receive information of the disease before, and probably should not have heard of it if a death had not taken place.

3. I do not receive any information from the Poor-law Medical Officer or the clerks, with respect to the new cases of sickness or of deaths among pauper patients; consequently I am not able to make the quarterly returns required by the order of November IIth, I874 Mr. Lambert's circular of March 23rd, I874, has done no good in my district. I am convinced the Poor-law Medical Officers will not give the information, because they are paid nothing for doing so, and I think it is very sensible of them.

Another writes : I cannot get direct information as to the existence of epidemic disease; what $I$ have to rely on is the return of deaths from the registrar.

Another writes : "Some of the district medical officers in my union forward notice of cases of infectious disease to me, and others will not, or, at least, do not do so ; none are paid extra for doing so ; nor do I see that they could well ask for anything specially for doing so, as it ought to be one of their regular duties, as it is that of the clerks, to send copies of entries of new cases of pauper sickness. As a matter of fact, the number of notices which most of the district medical offcers in my district send per annum is so small, that remuneration for them, based on any reasonable consideration, would only amount to a few shillings a year."

[I quote the writer, but I do not agree with him that the cases of the clerk and the district medical officer are at all the same. The first is generally paid a good salary, the latter are notoriously ill paid ; it is no answer that they voluntarily take their appointments; many are compelled to take and retain these pecuniary worthless offices because they have to keep some one else out. If extra work is demanded, extra pay should be accorded.-J. R.]

r. In the midst of my district are two local board districts which did not join the combination; one pays $£ 50$ a year (a fair salary), and the appointment is sanctioned by the Local Government Board; the other pays $£$ ro (a ridiculous salary), and is not sanctioned by the Local Government Board.

2 and 3. I have no difficulty whatever in obtaining reliable information of epidemic diseases from the medical men and also from Poorlaw medical officers. I am on remarkably good terms with the profession in my district, and, of course, on that entirely depends the successful working.

4. The muddle is that the Local Government Board have given no intimation of any policy as regards the appointments. As the Act is only on its trial, I don't think that we can expect much. They certainly ought to initiate a policy, and carry it out to the best of their ability ; and, until they do that, the combined appointments are practically valueless. I should not have retained mine had I not been exceedingly comfortable in it.

The last quarterly returns issued by the Local Governnent Board are so very difficult to make out, and so utterly valueless when made out, that it plainly shows the ignorance of the working of such appointments by the gentleman who drew them up. He cannot have been a medical man, and certainly can know nothing of Hospital practice.

In November of 1872 , the Guardians of the Neath Union in Glamorganshire advertised for a medical officer of health. No salary was named, but the successful man was to devote all his time to the work, and he was to go through another election the following March. In March I was re-elected, without opposition, for twelve months only, at salary of $£ 300$, and debarred from private practice. Maiters went on comfortably for a year, and I was again re-appointed for twelve months. However, at this time a re-arrangement of the Union was being contemplated, resulting in the separation of five parishes, in March of 1875 , to form another union. I should state that, previously to this, my district comprised an area of over 153,000 acres, with a population of 49,000 (estimated by myself). I could now gather, from certain rumours, but received no official intimation, that my tenure of office was not to be of long duration. In March of 1875 , they were gracious enough to allow me to "hang on" for six months longer at the old salary. Then in the following September I was asked if I should like to continue for another six months, with a salary at the rate of $\$ 200$ per annum, and in those six months to make sufficient head-way in private practice to enable me to keep myself for the future. Not expecting such shabby treatment as this, I kept on for awhile until I could suit myself. In November I resigned. No substitute was appointed until March, when the Poor-law medical officers were elected officers of health for their relative districts, with salaries amounting altogether to less than $£$ Ioo.

In October, I consulted with Dr. Buchanan and Mr. Simon. The latter gave me a letter of introduction to Mr. Sclater-Booth, with whom I had a long interview. He of course could promise nothing; and when I alluded to being dealt unfairly with by the Board, quietly stated that I had taken the appointment with my eyes open, and that, as a young man, I ought to consider myself very fortunate in having had such experience. From my experience with Sanitary Boards, it will require some very heavy pressure to make me take it up again, with the law in the state it now is.

I. My district is irregular, as it includes an entire union, minils one town, which chose to keep out. This causes much extra difficulty in apportioning statistics.

2. I have no information of infectious sickness.

3. My clerk complies with the letter of the Act by sending me the Poor-law medical officers' sheets at the end of each quarter, for the purpose of filling up the quarterly schedules required by the Local Government Board. Of course, for purposes of preventive medicine it is a mere farce. He would, doubtless, do otherwise if paid.

4. The muddle arises from the want of backing up the medical officer by the central authority. By doing honest work 1 jeopardise my ap. pointment, and have done so. In such case, the Local Goveriment Board should certainly stand by officers who, holding their api)ointment subject to the approval of the Crown, are really the Cruwn's officers.

A Poor-law Medical Officer writes as follows. About two years ago, this was formed into a combined sanitary district, the rural and borough uniting, the rural consisting of the union district as accepted by the Poor-law. A medical gentleman was appointed at E- per annum; this broke down within the year, owing to some disagreement between the borough officials, who were afraid they were getting nothing for their money. A borough officer was then appointed at $£$ - which is still in being. The rural sanitary authority appointed two officers at $£-$ each, for districts north and south. This has broken down, and we have only one for the whole rural district, who lives in the borough, whereas they each lived at the extreme limits of their districts when separated. The present officer gets $f-$ per annum.

I was an applicant for the appointment when first formed, but was objected to because I was a Poor-law Officer in the district, but they nevertheless appointed a Poor-law Officer out of the district. The chairman said I should have obtained the appointment, but for this objection.

Yet my information, which is always asked for and obtained, so far as regards my district, is considered of the greatest importance. I virtually do all the inquiries, get the information, and communicate to the inspector and surgeon appointed, every case of fever ; recommend various sanitary alterations and drainage improvements, report nuisances, and get the thanks of the Rural Sanitary Board every year, publicly and privately, for my exertions in behalf of sanitary matters, which the inspector and surgeon appointed see carried out and get paid for. I only get thanks.

To show the inefficiency of the present appointed officers, and their futileness, I reported a case to the chairman of the Rural Sanitary Board, who resides in a populous village in the district. I said : "You have in your village two virulent cases of scarlet fever which will spread havoc amongst you ; I leave you to find it out and give the inforiration to your officers". Of course, he wrote to the officers, and they iaddled the villase for two days before they discovered them. He fiankly admitted that I had the advantage over the officers appointed, as $I$ had taken the necessary precautions, not only for isolation, but antiseptically, immediately on discovery.

I feel certain no case of fever could remain long in my district undiscovered, whereas the officers, being miles away, would never hear of it, unless through some agent such as myself. The Poor-law surreon, practising among the class of fever-carriers, is the one, par excillence, to meet with fever in its haunts, and there and then to put a check upon it without circumlocution; and thence I argue that he who discovers the plague-spot, and inaugurates the remedy, should be paid for it. I constantly visit cases of what are called trifling ailments, and have detected cases of contagious fever, and kept the children from school, this recognition being sufficient to prevent the spread through the village. This is a constant source of infection in villages, the real focus whence a whole village may be stricken down. 